\title{
De Dissonâncias e Traduções: territorialidades e gestões no Alto Rio Negro
}

\author{
Aline Fonseca Iubel ${ }^{1}$ \\ ${ }^{1}$ Universidade Estadual de Campinas, Instituto de Filosofia e Ciências Humanas da \\ Unicamp, Campinas, SP, Brasil
}




\section{Resumo}

Desde antes da demarcação das primeiras terras indígenas no Alto Rio Negro (há mais de 20 anos), população e lideranças indígenas regionais atuam constantemente em processos de reflexão e de avaliação de algumas de suas experiências de gestão territorial e relações com o Estado. Atualmente, desenvolvem essas atividades com os instrumentos da Política Nacional de Gestão Ambiental e Territorial de Terras Indígenas (PNGATI). A intenção deste artigo é fazer uma reflexão a partir de algumas das dissonâncias e das traduções implicadas nas relações entre indígenas e Estado no tocante às territorialidades e às gestões destas (que envolvem também, evidentemente, a gestão da própria relação que se quer estabelecer com o Estado, do ponto de vista indígena).

Palavras-chave: Territorialidades. Alto Rio Negro. Dissonâncias.

\section{Abstract}

Since before the demarcation of the first indigenous lands in the upper Rio Negro (more than twenty years ago), indigenous population and their regional leaders constantly work in processes of reflection and evaluation of some of their experiences of territorial management and relations with the State. Nowadays they carry out these activities with the instruments of the National Environmental and Territorial Management of Indigenous Lands Policy (in Portuguese "PNGATI"). The main purpose of this article is to reflect, based on some of the dissonances and translations implied in the relations between indigenous and state, how the territorialities and the managements of the same ones also involve the management of the very relation that one wants to establish with the State, from the indigenous point of view.

Keywords: Territorialities. Upper Rio Negro. Dissonances. 


\section{Introdução}

O que faz a guerra é precisamente essa distância inevitável que nela o real toma em relação a seu modelo: pensar a guerra, em suma, é pensar como ela é levada a trair seu conceito. François Jullien. (Tratado da Eficácia, 1998)

G ostaria de começar este texto tomando a liberdade de trocar, da epígrafe acima, a palavra guerra por terra. Assim, teríamos a seguinte frase: "pensar a terra, em suma, é pensar como ela é levada a trair seu conceito". É o que tem sido feito, em diferentes instâncias e de diferentes modos, pelos povos indígenas do Brasil. Aqui, "pensaremos terra" e "trairemos seu conceito" a partir de um diálogo com os indígenas do Alto Rio Negro e seus pensamentos/ações acerca da(s) terra(s), do(s) território(s) e da(s) territorialidade(s) implicados nas políticas de gestão territorial e ambiental ${ }^{1}$. Pretende-se refletir sobre algumas dissonâncias e traduções efetuadas no âmbito das atividades desenvolvidas naquela região no escopo da Política Nacional de Gestão Territorial e Ambiental de Terras Indígenas (PNGATI), principalmente a partir da confecção dos Planos de Gestão Territorial e Ambiental (PGTAs). Para isso, o presente artigo será dividido em três partes.

Na primeira, parte-se de algumas considerações locais posteriores à demarcação das terras indígenas na região e de dados referentes ao processo demarcatório, para refletir as noções de demarcação e território, a partir da ideia de dissonância. Na segunda parte, adentrase na etnografia a partir de exercícios de tradução que vêm sendo realizados pelos indígenas da região nas diversas oficinas e em diferentes momentos de implementação da PNGATI; o que, evidentemente, implica em fazer uma (ainda que) breve e inicial reflexão sobre a ideia 
de tradução. Por fim, retomam-se as ideias de dissonância e tradução, vinculando-as ao que seria uma concepção local de política/guerra. Afinal, muito do que se apresentará aqui em relação às experiências de gestão territorial e em relação às concepções de terra e território, pode ser lido também sob a ótica da(s) guerra(s), sejam elas reais, conceituais, jurídicas, ontológicas (Almeida, 2013) ou de mundos (Latour, 2002) $)^{2}$.

\section{Demarcações: dissonâncias e tensões}

Em 2013, conversando com o líder indígena, de etnia Baré, que presidiu a Federação das Organizações Indígenas do Rio Negro (Foirn) ${ }^{3}$ durante o período de luta pela demarcação de terra naquela região ${ }^{4}$, ele me disse, num certo tom cansado e crítico, que a demarcação "não era essa coisa toda". Em suas palavras:

[...] Terra Indígena é terra da União. Quer dizer, o governo pode fazer o que quer, os índios apenas têm o usufruto exclusivo. O que também não é verdade, porque não é exclusivo. Nós negociamos e depois de noventa dias saiu a declaração. Mas, pra quê isso? A gente não estava sabendo das consequências disso, porque depois que a terra foi demarcada apareceu Chico Mendes [Instituto Chico Mendes da Biodiversidade [...] vieram lá do Xapuri pra cá dizer que a gente não podia tirar madeira, não podia fazer roça grande. Aí começaram os problemas. Quando a terra não era demarcada, os comerciantes saiam daqui, enchiam o barco de mercadoria de primeira necessidade - cafezinho, uma roupinha - e saiam pra vender sua mercadoria e trazer produto das comunidades - fruta, peixe, farinha. De qualquer maneira, o cara lá no alto do rio estava sempre esperando e já preparava um tanto de farinha, por exemplo, pra trocar por outras coisas. Ele esperava, não precisava vir pra cá. Depois que foi demarcado não pode mais ter comerciante branco circulando por aí. O povo começou a sentir aquele impacto. (Entrevista com Bráz França, 2013, grifos meus)

É claro que tal fala me causou estranhamento. Num contexto nacional em que se vê quase que diariamente índios sendo massacrados em suas lutas por terras ou sendo dizimados por não ter onde viver, 
que sentido poderíamos encontrar para essa crítica à própria ideia de demarcação? O que nós, antropólogas e antropólogos, podemos fazer diante de falas aparentemente dissonantes, inesperadas e geradoras de tensão?

Em pesquisa anterior ${ }^{5}$, aquela fala permaneceu latente, como espécie de ruído que mereceria ser refletido posteriormente. Pareciame não se tratar simplesmente de uma fala contra-o-Estado (ainda que também), se pensarmos num modo atualizado dessa concepção clastreana. Afinal, a demarcação, mais até do que a participação indígena nas políticas eleitorais, por exemplo, é a atuação e atualização do próprio Estado: cercamento, esquadrinhamento e territorialização. Uma atuação sobre a terra, sobre todas as possibilidades de terra que poderiam ser aventadas pelos índios da região, transformando-a em território (demarcado). Atuação-do-Estado que converte o performativo em prescritivo, a posse (indígena) em propriedade (do Estado), impondo limites e fronteiras cuja correspondência ao território vivido é impossível. Mas o problema aqui não está só no confinamento: está no fato de que a própria métrica do terreno impõe uma mudança nas relações, como já mostrava Weber no "Direito Agrário Romano":

[...] a primeira inter-relação que tentei demonstrar é a que deve manifestar-se necessariamente entre o tipo de medição dos terrenos e a relação jurídico-pública do território a que os terrenos pertencem, além das relações jurídicas privadas dos fragmentos particulares. Não posso dizer até que ponto consegui precisar o caráter dessas relações, mas me parece que em si já é um êxito poder considerar que se adquiriu - como gostaria de crer - a consciência de que há uma conexão e que ela pode ser encontrada. (Weber, 1994, p. 2)

Assim, se hoje a demarcação pode aparecer em discursos indígenas como espécie de dissonância, é porque essa possibilidade (da dissonância) cabia dentro das concepções de demarcação desde que esta ideia foi apresentada aos povos indígenas do rio Negro. Mas, também, porque dissonâncias (e discordâncias) foram efetivamente produzidas e explicitadas antes e depois do processo de demarcação. 
Façamos um exercício imaginativo: estavam os índios, vivendo naquela região, a seus modos, mas em contato com diversas gentes (os que chamamos brancos, inclusive), quando, de repente, começa-se a falar em algo que se chama "demarcação". É difícil reconstituir as trajetórias que tal termo percorreu na região, adquirindo diferentes tons (cores e/ou sons) e sentidos em diferentes localidades e tempos ${ }^{6}$. Mas, não é impossível imaginar que ela tenha recebido mais de um significado, e, muitas vezes, tenha disputado os significados e sentidos acerca das concepções de demarcação. Aqui reside a utilidade da ideia de dissonância. A inspiração aqui é a música, em que dissonância aparece como falta de harmonia e discordância, relação entre notas próximas que gera tensão, ou ainda, combinação simultânea de notas convencionalmente aceitas como em estado de irresolução harmônica. Dissonâncias, discordâncias e tensões podem tanto aparecer imediatamente, diante de uma proposta efetiva de demarcação, por exemplo, mas, também podem surgir conforme passa o tempo. A esse tempo que transcorre se sobrepõem novas relações ou transformações em antigas relações.

Os processos demarcatórios são, dentre outras coisas, marcações das relações entre indígenas e Estado, que implicam em um exercício de tradução, da "terra que é vivida" pelos povos indígenas em um conceito jurídico e estatal. Como se diz há um bom tempo, trata-se de um esforço de enquadramento das territorialidades ameríndias na territorialidade dos Estados nacionais. No caso brasileiro, as demarcações se fundamentam juridicamente no conceito de "terra tradicionalmente ocupada". Como consta no projeto do Laboratório de Antropologias da T/terra (2017), esse conceito de "terra tradicionalmente ocupada", para começar, cria uma "powerful demarcation", que nem sempre se transporta muito bem. Isto é, o enquadramento pretendido nem sempre é bem-sucedido. O que algumas pesquisas têm evidenciado é que a tradução concreta de demarcação na vida indígena prolifera incertezas: os limites entre "tradicional" e "não tradicional", entre "ocupar" ("permanentemente") e "não ocupar", por exemplo. Além disso, diversas etnografias têm demonstrado que critérios como "tradição" ou "ocupação permanente" são ora ignorados, ora deslocados. Mas, 
irrompem quase sempre em "(re)territorializações" nos termos das demarcações, configurando diferentes formas destes coletivos habitarem suas "terras demarcadas".

Tem-se, portanto, uma noção jurídica de "terra tradicionalmente ocupada", que precisa ser preenchida caso a caso nos relatórios de demarcação, de onde decorre um processo de "territorialização", ou, um enquadramento no ordenamento territorial operado pelo Estado. Como salienta Julia Miras (2017): ao ordenar sobre a terra dos índios o Estado lhes impõe o seu nomos - suas leis e ordem - que foi primeiramente imposto sobre a terra ${ }^{7}$. Além disso, esses processos não são instantâneos, vão sendo completados e constantemente ressignificados conforme o passar do tempo. Assim, não se pode ignorar a temporalidade da fala transcrita acima, proferida cerca de quinze anos após a demarcação das terras indígenas na região, momento de certo acúmulo de experiências de gestão e em que se começava a aventar a necessidade e possibilidade (mas também a imposição estatal) de um novo instrumento para gestão das terras indígenas, ou seja, quando já se começava a falar em PNGATI e em PGTA no Alto Rio Negro. Mas, olhemos um pouquinho o passado, para entender alguns meandros da demarcação que foi alcançada no Alto Rio Negro.

\subsection{Demarcação de Terras no Alto Rio Negro: traduzindo territorialidades em "territórios" indígenas/estatais}

Um primeiro diagnóstico oficial que visava fundamentar propostas de demarcação na região do Alto Rio Negro foi feito pelo antropólogo da Fundação Nacional do Índio (Funai), Peter Silverwood-Cope, em meados da década de 1970. Tratava-se do Plano Alto Rio Negro, um programa de desenvolvimento comunitário para os índios do Uaupés. Enfatizava-se, neste diagnóstico, que a região já se encontrava em avançado "processo civilizatório", decorrente da catequese e da educação, que implicava na "necessidade de consumo comercial" (Silverwood-Cope, 1976). A “ocupação indígena” de três áreas contíguas foi declarada pela Funai em 1979 - Pari-Cachoeira, Iauaretê e Içana-Aiari ( seguindo a divisão paroquial instaurada pelos salesianos). "Declaração de ocupação", no entanto, estava longe de significar demarcação e não 
satisfez as lideranças locais e regionais, que continuaram a reivindicar a delimitação do Alto Rio Negro como área única.

O desinteresse do governo em resolver a questão da demarcação das terras na região só aumentou quando, em 1982, uma comissão militar foi à região e expôs aos índios que o Exército se opunha à demarcação numa faixa de 60 quilômetros da fronteira internacional. Em meio a tantas propostas feitas pelos índios na década de 1980, “[...] no dia 4 de abril de 1986 o Presidente da Funai, Apoena Meirelles, anunciava à Associação da União da Comunidade Indígena do Rio Tiquié (UCIRT) que a decisão final sobre a proposta de delimitação na região estava fora do seu controle $[\ldots]^{\prime \prime}$, conforme consta em um texto de Dominique Buchillet, publicado em 1991, que reconstitui um pouco as tramas dessa história. Isso por conta da intervenção militar, através do Conselho de Segurança Nacional (CSN), órgão que prontamente foi identificado pelos índios como mais um obstáculo na luta pela demarcação. Os líderes da UCIRT trataram então de marcar uma reunião em Brasília, na qual apresentaram às autoridades (General, Ministro, Assessores e Presidente da Funai) sua proposta de demarcação como reserva indígena contínua. O General, por sua vez, rapidamente rechaçou tal proposta por se tratar da faixa de fronteira, argumentando que a reserva indígena não permitiria a entrada de brancos e que o "estado de aculturação" dos índios da região não justificava uma tal medida. A contraproposta do governo era a criação de Colônias Agrícolas Indígenas. Um trecho do Relatório da Assembleia da UCIRT dá a exata dimensão do jogo inescrupuloso feito pelas autoridades governamentais:

Os representantes indígenas posicionaram-se em favor da terra coletiva, isto é, a demarcação de terra indígena contínua. Foi nesse momento que o general ficou muito furioso e disse que o Presidente Sarney não assinaria os decretos das reservas indígenas [...]; que o governo não pode demarcar terra na faixa de fronteira só para uma etnia indígena [...]; que a faixa de fronteira pertencia a todos os brasileiros, isto é, para todas raças defender a nação. No momento tenso o Dr. Gerson Alves da Silva [assessor para os assuntos indígenas do Ministro do Interior] encontrou no Estatuto do Índio uma razão 
para falar sobre a Colônia Agrícola Indígena. E, diante desse argumento, o General viu a saída para solucionar o nosso problema, isto é, que teríamos que aceitar a Colônia Agrícola Indígena ou senão nós perderíamos todos os direitos sobre a terra; prosseguiu que os índios Tukano já eram aculturados demais, que nós andávamos bem trajados [...] e, por isso, não poderíamos viver num jardim zoológico ou numa reserva indígena. Para o nosso desgosto o Presidente da Funai disse que não tínhamos nenhum amparo legal para defender a reserva indígena porque todos os trabalhos feitos (até agora) não valiam nada em relação a faixa de fronteira e/ou área de segurança nacional, e sim, que teríamos que aceitar a colonização indígena. (Relatório da Assembleia, Pari-Cachoeira, nove de junho de 1986, apud Buchillet, 1991)

Essa assembleia extraordinária convocada pela UCIRT em PariCachoeira produziu mais um documento recusando de maneira formal o modelo de Colônias Agrícolas proposto pelo CSN. A rejeição da proposta de Colônias Agrícolas foi também um dos motes da Segunda Assembleia Geral dos Povos Indígena do Rio Negro, de 1987. A experiência anterior dos líderes da UCIRT, naquela reunião em Brasília, parecia, no entanto, levá-los a um caminho totalmente oposto. Eles estavam cientes da irreversibilidade desse processo, já que a implantação do Projeto Calha Norte (PCN) era mais do que real na região do Alto Rio Negro ${ }^{8}$. Tentou-se convencer os mais de 300 índios presentes na Assembleia dos possíveis benefícios do PCN e da demarcação segundo o modelo de Colônias Agrícolas, mas os agentes governamentais não obtiveram sucesso.

Os passos seguintes foram a transformação de três Colônias Indígenas em Áreas Indígenas (categoria que era usualmente destinada a grupos indígenas relativamente isolados), em 1989, e a homologação, em 1990, de onze Áreas Indígenas na região do Alto Rio Negro e nove Florestas Nacionais (que não eram de uso exclusivo dos índios). Esse foi o fim de um ciclo, que coincidiu (ou não) com o final do governo Sarney e das verbas para o PCN. Concomitantemente, vários líderes e organizações indígenas tiveram suas imagens desgastadas e caíram em descrédito político. Além disso, uma das mineradoras mais atuantes na região se retirou, desativando o sistema de segurança 
e outros benefícios que era a base da aliança dos índios com a empresa para se livrar da tormenta das invasões e conflitos com garimpeiros ilegais. Como relata Beto Ricardo em um texto, também de 1991:

[...] restou um dossiê de dívidas das lideranças com a empresa: passagens aéreas, estadias em hotéis e serviços de saúde, ardilosamente acumuladas, repassadas e utilizadas politicamente como forma de controle e pressão sobre os "representantes". Os índios Tukano que haviam se tornado funcionários da Funai e controlado cargos importantes do órgão a nível local e regional para a intermediação das negociações, foram demitidos sumariamente, quando não alvo de processos administrativos por questões financeiras. (Beto Ricardo, 1991, p. 3)

Nesse processo de demarcação parcial e de forma descontínua das Áreas Indígenas, algumas lideranças se enfraqueceram, outras se constituíram ou ganharam espaço. Além disso, mudanças na legislação e na sistemática de demarcação de terras indígenas, que passaram a exigir a aprovação dos grupos indígenas interessados em relação aos limites das propostas de demarcação, e a crescente organização do movimento indígena no Alto Rio Negro conduziram a mais uma tentativa de pressionar o governo à demarcação dos mais de oito milhões de hectares que deveriam compor, segundo os índios e os laudos antropológicos, a Área do Alto Rio Negro. Em carta destinada ao Presidente da República, os índios, que passaram a assinar como Foirn, argumentavam que quando os militares chegaram prometeram demarcação, transporte, saúde, barcos, postos de saúde e projetos econômicos que dariam rendimentos aos índios; falaram também sobre a terra, que partiriam em pedacinhos, um para cada povo. No entanto, como se viu, esses pedacinhos, chamados Flonas, foram subtraídos das terras indígenas e as áreas demarcadas nunca contemplaram o "território tradicionalmente ocupado" pelos índios.

Depois de uma série de despachos entre diferentes instâncias do governo e extrapolando os limites do Alto Rio Negro (incluindo o médio rio Negro e regiões adjacentes), foi somente entre dezembro de 1995 e maio de 1996 que o então ministro da Justiça (Nelson Jobim) declarou de posse permanente dos índios e determinou à Funai a demarcação 
administrativa de cinco Terras Indígenas contíguas na região do alto e médio rio Negro: Médio Rio Negro I, Médio Rio Negro II, Rio Téa, Rio Apapóris e Alto Rio Negro. Em 1996, ocorreu uma reunião na sede da FOIRN, em São Gabriel da Cachoeira, para tratar do modelo de demarcação física.

A homologação dessas cinco Terras Indígenas aconteceu em 14 de abril de 1998, e uma cerimônia foi realizada no dia seguinte na maloca da Foirn, com a presença de líderes indígenas e autoridades governamentais. Tal cerimônia foi presidida pelo então presidente da Foirn, Pedro Garcia, o qual chamou para compor a mesa o Ministro Renan Calheiros; o Presidente da Funai, Sullivan de Oliveira; Áureo Faleiros, também da Funai; Ribamar, da Coordenação Regional da Funai; Beto Ricardo, do Instituto Socioambiental e o coordenador operacional da demarcação, o ex-presidente da Foirn, Bráz de Oliveira França. Este foi o primeiro a fazer uso da palavra, declarando:

Na verdade, a nossa sensibilidade, a nossa gratidão pelo que ocorreu, pelo que está ocorrendo, pelo que está acontecendo, pela realidade que está se vendo, se dá graças ao esforço conjunto de todo movimento indígena, de toda a sociedade que se envolveu para que as terras, na verdade, as terras indígenas fossem realmente efetivadas como de posse permanente dos seus ocupantes tradicionais. Em nome de toda essa sociedade que se envolveu impecavelmente para a luta dessa conquista, eu quero, em nome de todos, agradecer mais essa vitória registrada em nossa história do nosso movimento da nossa luta e do nosso cotidiano. [...] Cabe a nós, então, unicamente, essa grande honra de, a partir desse momento, dizer realmente que nosso futuro e o futuro de nossa geração está garantida e como garantia dessas terras ora homologadas, demarcadas - perdão reconhecidas, demarcadas e ora homologadas, queremos festejar com tanta gratidão, a segurança mais uma vez do nosso grande futuro. (Discursos e entrevistas da Cerimônia de Homologação das Terras Indígenas do Rio Negro na Maloca da Foirn, São Gabriel da Cachoeira, 15 de abril de 1998)

Na sequência, ele ressaltava também que aquele não era o fim da luta, mas era o início de “[...] uma longa caminhada para uma 
verdadeira conquista na área social e na área da segurança [... $]^{\prime \prime}$, cabendo, dali para frente, aos povos indígenas, órgãos ambientalistas, ecologistas e governo, proteger essas terras. Essa fala, laudatória da demarcação, e aquela com que abrimos a primeira parte deste artigo, crítica à ideia de demarcação, foram proferidas pelo mesmo líder, em momentos diferentes. Em certa medida, elas confirmam algo que já foi aventado por Carneiro da Cunha (2012, p. 102) a respeito da posição aparentemente bizarra que viria a ser ocupada ao longo dos últimos trinta anos pelos líderes indígenas:

Trata-se - trocando em miúdos - de garantir as terras, as condições de saúde, de educação; de respeitar uma autonomia e as lideranças que possam surgir: lideranças que terão de conciliar uma base interna com o manejo de instituições nacionais e parecerão por isso mesmo bizarras, com um pé na aldeia e outro - por que não? em tribunais internacionais.

Sublinhe-se na formulação da autora que tanto em suas relações com os seus "parentes indígenas" quanto com outros agentes (sejam estatais ou em "tribunais internacionais"), os líderes são ora laureados ora criticados, e, de modo paralelo, também atuam "com" e "contra" (muitas vezes, simultaneamente).

A fala de Bráz menos otimista e posterior à demarcação sugere também que a transformação não se deu somente no sentido almejado. O "desenvolvimento" e o "progresso", citados em seu discurso de 1998, não ocorreram como o esperado. No entanto, para que aquela fala mais pessimista (ou realista) não pareça uma crítica infundada e irrevogável do processo de demarcação de terras indígenas, é preciso esclarecer que, a despeito dos efeitos inesperados ou de algumas consequências negativas, Bráz me garantiu que faria tudo do mesmo jeito novamente, lutaria pela demarcação, pela consolidação do movimento indígena e pela Foirn. Até porque, ele tem hoje (de modo mais claro que no passado) ciência de que "não seriam um papel timbrado e assinado pelo presidente da República mais uns pontaletes fincados nos limites da Terra Indígena" garantias de que os brancos evaporassem ou passassem a respeitar uma fronteira invisível e que até então não existia. Segundo, pois ele também reconhece que sempre houve todo tipo de branco, uns 
mais outros menos amigos, para não falar daqueles atrozes e violentos. No caso das relações comerciais, Bráz considera, inclusive, que não importa tanto o fato do comerciante ser branco, caboclo ou índio, o que importa é teor da relação, na qual, invariavelmente, o índio é a parte mais fraca, sendo explorado e desprivilegiado. Passados três anos daquela fala, vive-se no Brasil um momento de acirramento e retrocessos na relação entre índios e Estado, sobretudo no tocante às demarcações. São diversas as tentativas de revisão e diminuição de terras já demarcadas; quase todos os processos em andamento estão parados em gavetas e mesas de ministros; tenta-se, de modos inescrupulosos, modificar os modos como são realizadas as demarcações. Renova-se, assim, o sentido da assertiva de Bráz de que "Terra Indígena é terra da União" e que isso significaria que "o governo pode fazer o que quer". Atualmente, parece que o que o governo quer é transformar as terras indígenas em "terras produtivas" e os indígenas em "trabalhadores" para o Estado. ${ }^{9}$

\section{PNGATI: constante exercício de tradução}

Para a região do Ayari, o PGTA não é uma novidade. Muitos entenderam que nossos antepassados tinham o seu plano bem organizado e com respeito a todas as coisas que a natureza oferece. Sabiam como valorizar, preservar e gerir a sua terra como patrimônio. Nessa atividade de levantamento de informações, as comunidades acreditam que estamos avançando nosso desafio de governar e viver bem na nossa terra. (Silvério Silva Lima, pesquisador indígena, Boletim Governança e Bem Viver Indígena: Planos de Gestão Territorial e Ambiental das Terras Indígenas do Alto e Médio Rio Negro n. 2, p. 19, grifos meus )

A fala do pesquisador que tem trabalhado nos censos e levantamentos realizados pela PNGATI na região do Alto Rio Negro sugere a existência de um exercício de compreensão da nova política - externa - nos termos do que era e é vivido localmente. Esse exercício pode ser tomado como espécie de tradução, ou, transformação de conceitos, de aceitação ou recusa de ideias. 
Mas, vamos entender primeiramente o que é a tal PNGATI e ter uma breve noção de algumas iniciativas de gestão anteriores a ela promovidas pela FOIRN e outros parceiros institucionais, para não parecer que os índios daquela região estão partindo do zero e que nunca ouviram falar no termo "gestão". Privilegiei aqui compartilhar informações retiradas das publicações vindas à luz nesse processo, elaboradas de modo interinstitucional por indígenas, Foirn, Instituto Socioambiental e Funai, e que estão sendo chamadas de "Boletins de Governança e Bem Viver Indígena" (2015 e 2016). Parte-se aqui de uma seleção local do que se quer ou não enfatizar a respeito da política nacional.

A Política Nacional de Gestão Ambiental e Territorial das Terras Indígenas é um decreto federal de 2012, assinado pela presidência da república e pelos ministérios da justiça e meio ambiente, cujo objetivo é:

[...] garantir e promover a proteção, a recuperação, a conservação e o uso sustentável dos recursos naturais das terras e territórios indígenas, assegurando a integridade do patrimônio indígena, a melhora da qualidade de vida e as condições plenas de reprodução física e cultural das atuais e futuras gerações dos povos indígenas, respeitando sua autonomia sociocultural, nos termos da legislação vigente. ${ }^{10}$

Hoje, é no âmbito da PNGATI que os índios têm realizado novos censos, levantamentos, pesquisas e (re)pensado ações para as suas terras, atividades em muito semelhantes aos modos de atuação estatais. Não por acaso, os boletins utilizam o termo "governança"11 e a gestão política e executiva da agenda para elaboração dos PGTAs é realizada por meio de diferentes instâncias, organizadas conforme funções e responsabilidades diferentes, que incorrem em organogramas baseados em formas de organização estatais, burocráticas ou de movimentos sociais.

A ideia de "governança", que aproxima as experiências de gestão do território de um modo em algo "estatal" (com muitas aspas), também ganhou força durante os anos posteriores à demarcação, já em iniciativas de gestão anteriores à PNGATI. No primeiro boletim, há uma página dedicada a apresentar algumas dessas iniciativas, que resultaram 
em projetos de piscicultura e segurança alimentar; na instalação de redes de radiofonia; em levantamentos e censos socioambientais; em projetos nas áreas da saúde, da educação, do artesanato, do turismo e de comercialização de produtos indígenas com valor agregado; em formação de gestores de projetos e; em mapeamentos e pesquisas interculturais com formação de pesquisadores e agentes indígenas. Diversas publicações foram produzidas no âmbito de alguns desses projetos. Trata-se de um conhecimento acumulado, o qual, somado aos "planos que os antepassados tinham" sobre como "valorizar, preservar e gerir a terra como patrimônio", como apontado por Silvério, permite avançar no sentido, também sugerido pelo pesquisador indígena, de "governar e viver bem na terra".

Há aqui um modo indígena de fazer algo que pode se assemelhar àquele com que agentes que trabalham ou operam para o Estado o fazem, ou, ao que eles estão chamando de "governar e viver bem na terra". Claro que há que se ter cautela com o uso deste palavrão Estado -, pois a referência aqui é antes a um modo que a um agente específico. Um modo, aliás, incorporado também pelas organizações do movimento indígena, pela Foirn, pelas ONGs, por lideranças e pesquisadores (indígenas e não indígena). A diferença entre esses agentes reside muito mais nos objetivos que nos meios. ${ }^{12}$ Um exercício de tradução realizado por uma liderança Baniwa sugere quão diferentes podem ser os objetivos locais e estatais obtidos (ou almejados) com os mesmos recursos.

Em fevereiro de 2016, André Baniwa publicou em um blog e em seu perfil no Facebook o que ele chamou de lição de "interculturalidade". Reproduzo aqui o trecho na íntegra.

Assim se traduzirmos a extensa frase do "PGTA" [Plano de Gestão Territorial e Ambiental], a palavra seguinte é "de" em Baniwa também tem sentido como "linako", ou seja, "sobre". A palavra "Gestão" refere-se ao "ideenhikhetti", ou melhor, "trabalhar". A palavra "Territorial" em Baniwa é "Wahipaite", ou seja, "nossa terra". O "e" é "nheette" em Baniwa não tem diferença da língua Portuguesa. A palavra "Ambiental" significa "weemakawa". Em resumo, a frase do "PGTA" depois de sofrer tradução intercultural em 
Baniwa fica seguinte frase: "Wadzeekatawa ideenhiketti linako wahipaite nheette weemakaawa liko nako".

Em língua Portuguesa fica assim, portanto: "Para fazermos e trabalharmos sobre a nossa terra e no local onde moramos". Ele ainda acrescenta que a palavra "linako", quando traduzida como "sobre", refere-se ao plano ideal, porém, o mesmo termo pode ser traduzido por "no" e passa então a se referir à prática no lugar. E mais:

[...] a palavra 'sobre' podemos ainda traduzir interculturalmente neste contexto como 'linakoapanina', ou seja, regras, ética sobre um território e um lugar onde se habita. Isso é muito mais do que fazer etnomapeamento, etnozoneamento, pensar em obras necessárias, etc.

Assim como boa parte dos índios americanos, André está longe de ser monolíngue. No Alto Rio Negro é comum os índios falarem pelo menos três línguas: a do pai, a da mãe (que quase nunca é a mesma, pois a preferência regional é pelo casamento com exogamia linguística) e o português ${ }^{13}$. Em geral, também falam espanhol e entendem ou falam nheengatu (língua geral). Aquele exercício de séries de traduções feito por André não é novidade, portanto. Enfatize-se que há, no Alto Rio Negro, mas também em outros lugares, uma certa "tradição de traduzir". Um dos passos na elaboração dos PGTAs, por exemplo, é a "produção de resumos e traduções dos PGTAs em línguas indígenas" (etapa prevista para o terceiro ano da elaboração dos planos). O que confirma a importância que nós, antropólogas e antropólogos, devemos conferir a esse tipo de exercício. Não desconsidero que os debates sobre tradução são antigos e que há uma série de importantes referências a serem incluídas, mas, quero apenas ressaltar que se trata aqui de pensar tradução enquanto ação política mais do que linguística ${ }^{14}$.

Em viagem a campo realizada em setembro de 2016, tive a oportunidade de ficar alguns dias em uma comunidade Baniwa, no rio Içana (distante cerca de um dia de viagem de São Gabriel), durante a I Conferência de Educação e Organização Social Baniwa e Koripako. Pude então conhecer e conversar com alguns dos pesquisadores indígenas envolvidos nos trabalhos de levantamento de dados da PNGATI junto às comunidades da região. Tanto as diversas falas e apresentações 
que compuseram a reunião, que durou cinco dias, quanto minha aproximação desses pesquisadores me instigaram a fazer com eles um primeiro experimento. Eu realizei o mesmo exercício depois, de volta à São Gabriel, com falantes de outras línguas, mas me atenho aqui ao exercício realizado entre alguns falantes de Baniwa, para manter alguma espécie de controle.

O exercício consistia em fazer listas com alguns dos termos que mais aparecem na PNGATI. As listas eram feitas por eles e não foram todas iguais. Os termos mais recorrentes foram: política, plano, gestão, território, terra, mundo, ambiente, chefe, cultura, cuidar, governo, administrar, dentre outros. Feitas as listas, a proposta era que eles traduzissem para suas línguas e dessem, em português, uma definição mais ampla do sentido/significado (assim como feito por André).

Diante desse exercício, algumas primeiras impressões podem ser apontadas: a tradução de alguns termos varia de acordo com o pesquisador interlocutor (diferença que pode ser resultante da região de origem do pesquisador; de sua formação profissional ou trajetória pessoal; até mesmo do clã a que pertence - por exemplo, um clã de chefes traduz certa palavra por outra que pode não ser a mesma que vem a ser utilizada por um clã que não seja de chefia). Atendo-se aqui a um dos termos recorrentes dessas listas - gestão -, observa-se que na tradução feita por André ela reaparece em português como "trabalhar (sobre)", enquanto em outra lista foi traduzida por "lideenhikanna" e retraduzida por "forma de gerir e administrar que está relacionada com a preparação, organização e estruturação de um determinado objetivo". As diferenças entre os termos escolhidos por um ou outro pesquisador para traduzir uma mesma palavra do português para sua língua refletem encontros ou embates entre diferentes "tradições" e "traduções". Numa tradução o termo "gestão" aparece como "trabalho", em outra, soma ao "trabalho" um "determinado objetivo".

Como colocado no trecho da fala que abriu essa segunda parte do artigo, mesmo antes da existência de um PGTA, os índios tinham um "plano" e sabiam "gerir a sua terra como patrimônio". O que eles não sabiam é que isso poderia interessar também ao Estado e aos brancos - que estão, sem dó nem piedade, acabando com a Terra (com 
"t" maiúsculo). Assim, eles estão agora inventando localmente vários sentidos para o termo "gestão", sentidos que, conforme começa a ficar demonstrado por uma etnografia ainda incipiente, nem sempre são os mesmos usados pelos indígenas e pelo Estado. Uma primeira hipótese é de que estejamos aqui diante do que foi apontado por Marcos Matos (2014) a respeito da incompatibilidade entre uma arte da atenção e o trabalho de gestão. Segundo o autor:

[...] o contraste entre esses dois conceitos é cada vez mais urgente, principalmente quando observamos que "gestão ambiental" tem se tornado linguagem hegemônica do indigenismo e do ambientalismo brasileiro. (Matos, 2014, p. 15, nota 65)

Ele sugere então que, para elaborar esse contraste, o conceito de "faire attention", de Isabelle Stengers, é imprescindível, já que é uma arte tanto "oposta à necessidade do desenvolvimento e da inovação" (que muitas vezes não é contemplada nos projetos de gestão territorial e ambiental indígenas), quanto de tomar cuidado com as consequências de seus atos. É o que as "gestões indígenas", na contramão das gestões estatais, sobretudo no tocante ao ambiente e aos recursos naturais, mostram. Os indígenas estão, sem dúvida, mais alinhados a uma ideia de "tomar cuidado" do que de "desenvolvimento a todo custo"; estão mais alinhados a uma ideia de gestão ambiental que contempla a dimensão do cuidado do que a simples administração. Ilustrativo disso é que eles acrescentam à ideia de trabalho a perspectiva de um "determinado objetivo". Este determinado objetivo é o cuidado (termo que em outras listas feitas com pesquisadores indígenas apareceu no sentido dado ao termo gestão). É o que eles pretendem alcançar com os tais PGTAs.

Beatriz Perrone-Moisés (2015, p. 9) chama atenção para o fato de que tradução - "[...] dos conceitos de uma Nação nos de outra, mas também criação de uma 'caixa de ferramentas analíticas', termos/ conceitos próprios que, por seu caráter transnacional, permitam a tradução unificada de 'different conceptions' [...]" - sempre foi um dos grandes desafios impostos à atividade antropológica. O que não é aplicado com o mesmo acuro a todo o léxico da disciplina. Algumas 
categorias seriam particularmente resistentes, segundo a autora. Nesse quadro da resistência (que é tanto das categorias quanto dos antropólogos) estaria, por exemplo, a categoria "política". Mas, o desafio de tradução também se coloca aos índios, os quais, muitas vezes, encontram saídas mais criativas, como parece sugerir acima André Baniwa. ${ }^{15}$ Assim, penso ser interessante a nós, antropólogos e antropólogas, explorar as consequências desse tipo de exercício. Ou, como sugere Perrone-Moisés (2015, p. 18-19):

Nesse sentido, o movimento empreendido aqui é o de que se aproximar do que o "native thinks" partindo da premissa de que, ao cabo de um esforço contínuo de tradução, por sucessivas gerações de indígenas vivendo em território brasileiro, está na hora de levar a sério o "português dos índios". Não parece cabido supor que pessoas em contato com a língua portuguesa, muitas vezes diário ao longo de sua vida, algumas das quais nasceram ouvindo português, outras que viveram anos em cidades brasileiras, tenham menos proficiência na língua do antropólogo e/ou menos capacidade de tradução que um etnólogo com talento e disciplina para o aprendizado de línguas indígenas.

Latour (1993), em The Pasteurization of France, sobretudo na segunda parte, chamada "Irreduções", elabora suas versões mais filosóficas dos conceitos de poder, agência, representação, etc. Para isso, utiliza o conceito de "translation", que significaria ao mesmo tempo "tradução" e "translação". Assim, toda tradução produziria adequações nas trajetórias dos actantes em relação, com um potencial não só de reconfigurar sua relação particular, mas os segmentos de redes dos quais eles são, eventualmente, porta-vozes, produzindo translações em cadeia. Acrescente-se a isso o fato de que as traduções realizadas pelos índios entre as mais diversas línguas, conforme demonstrado por André Baniwa, não são feitas sem reflexão e têm consequências diretas tanto em seus pensamentos quanto em suas práticas - ele salienta, por exemplo, que o PGTA seria "muito mais do que fazer etnomapeamento, etnozoneamento e pensar em obras necessárias", termos que aparecem como fundamento (e também limite) da proposta legal estatal. À proposta estatal de gestão, estabelecida por leis e resoluções, e que, 
por isso mesmo, é limitada e generalizante, somam-se, regionalmente, diferentes sentidos de cuidado e gestão. Mesmo sendo considerada como grande região, o Alto Rio Negro integra grande diversidade. No tocante à gestão territorial, por exemplo, há lugares (dentro dessa grande região) que estabelecem como objetos da gestão territorial o (re)conhecimento de "territórios tradicionais" e "lugares sagrados", há outros que privilegiam a criação e promoção de práticas de "turismo étnico e sustentável", ou ainda, a possibilidade de "pesca esportiva turística", alternativas de "exploração de recursos naturais", bem como iniciativas de proteção e fiscalização dos territórios ante garimpeiros e/ outros invasores. Vê-se, assim, uma diversidade de objetivos específicos preencherem a generalidade das proposições estatais.

\section{Considerações Finais}

Uma hipótese que aventei diante dessas duas experiências rionegrinas com suas terras - a demarcação e a PNGATI -, é que tanto a fala daquele primeiro líder quanto o que possa vir a acontecer com os usos dos instrumentos da PNGATI permitem pensar que os instrumentos não-indígenas ou estatais são "incorporados" no estoque indígena tal como o faz, para usar uma metáfora de Lévi-Strauss, o bricoleur. Esses instrumentos seriam semiparticularizados em função de um uso posterior, que promove avaliações, transformações, combinações, usos e descartes. Novamente, dependem da passagem do tempo para serem dotados de sentido. Mas, certamente extrapolam o sentido de um "estoque de ferramentas" que estariam disponíveis ao bricoleur. Passam, isso sim, por processos de invenção e inovação no mundo indígena, segundo um regime de criatividade que lhes é próprio (Leach, 2004).

Foi assim com as diversas propostas de demarcação, até que se chegasse a um consenso; é assim com a demarcação que foi possível e com a própria concepção de demarcação; é assim com a demarcação que é vivida; possivelmente, será assim com as novas experiências de gestão territorial e ambiental. De algum modo, manuseia-se ferramentas e matérias-primas estocadas em oportunidades anteriores, bem como se recompõe e atualiza este estoque para atividades futuras. Mas, isso é apenas uma parte do processo - incorporar ou semiparticularizar 
novos instrumentos (à la bricolagem). Outra parte, mais interessante talvez, é que nesses processos aprendem-se novas linguagens, novas escalas. Indígenas passam a responder simultaneamente a si próprios e ao Estado. As negociações têm de ser feitas e refeitas nessas duas frentes, constantemente.

É um outro Lévi-Strauss (2004), não o que opõe pensamento selvagem e pensamento domesticado (até porque essa oposição não faz nenhum sentido aqui), que diz que a emoção musical provém do fato de que a cada instante o compositor retira ou acrescenta mais ou menos do que prevê o ouvinte, e mais, que ele está sujeito a uma dupla periodicidade: uma de natureza individual e outra ligada à educação, à escala musical conhecida pelo compositor. Foi nesse sentido que recorri, desde o começo deste artigo, à metáfora da música. Pois creio que não estamos aqui em um campo onde haveria oposição entre duas lógicas de pensamento, mas, é como se assistíssemos a uma orquestra que toca a mesma música em duas escalas musicais diferentes: em se tratando de territorialidades, as terras demarcadas/estatizadas e as terras vividas/indígenas são simultâneas e constantemente atualizadas.

No Alto Rio Negro, os índios se apropriam do Estado, muitas vezes viram agentes deste, mas, o que é produzido deste encontro é um Estado diferente, que em alguma medida pode ser chamado de "indígena". Talvez não seja assim chamado apenas porque não há brecha na nossa constituição (como há em outras, que contemplam a ideia de estados plurinacionais, por exemplo). Mas, é, talvez, o que aparece na ideia de "governança" e nas iniciativas de "gestão territorial" (mais até do que nas de gestão ambiental).

Por isso, o recurso ao termo dissonância. Porque o que ocorre, muitas vezes, nesses encontros entre índios e Estado é tensão, uma tensão semelhante à que é sentida por quem ouve uma obra de Stravinski, por exemplo. Não se trata, evidentemente, de afirmar que o que eles fazem nesses processos de gestão territorial é inventar um "Estado indígena", ou operar segundo os modos estatais, pois, a parte mais importante nisso tudo é que eles o fazem de acordo com suas cosmologias, conhecimentos, tradições, lógicas e estruturas próprias, as quais englobam formas específicas de se relacionar com o que lhes 
é exterior ( tal como o Estado lhes é externo, por exemplo). André fala que "gestão de território" é mais do que fazer "etnomapeamento e etnozonemanto". Esse é um exemplo de tensão, entre termos, mas que tem encaminhamentos práticos. Outro tipo de tensão ocorre quando os pesquisadores chegam a uma comunidade, para aplicar o questionário do censo do PGTA, e a comunidade se recusa a responder, questionando a validade da PNGATI, do PGTA e dos trabalhos envolvidos neles. Isso aconteceu por exemplo, em poucas comunidades da região do Alto Rio Negro e Xié, conforme ressaltado no Boletim:

[...] como parte do trabalho foi realizado no período antes da eleição municipal houve poucos que decidiram não participar uma vez que o candidato com quem tinham fechado apoio era contrário às instituições participantes da elaboração do PGTA. Apesar de raro, este fato aponta para grupos que se articulam diretamente contra o avanço da gestão em Terras Indígenas, muitas vezes disseminando informações contrárias àquelas determinadas por lei e discutidas coletivamente. (Boletim Governança e Bem Viver Indígena: Planos de Gestão Territorial e Ambiental das Terras Indígenas do Alto e Médio Rio Negro n. 2, p. 18)

Por isso, a importância que se deu nesta etapa de recenseamento e pesquisa nas comunidades às apresentações que eram feitas da PNGATI e do que seja um PGTA para que então as pessoas pudessem decidir se participariam ou não. O que se coaduna com a importância dada pelos povos rionegrinos à tradução. Não esquecendo que, como lembra Mauro Almeida, "toda tradução é indeterminada e que a relatividade ontológica é inescapável. Não há como eliminar a relatividade ontológica com o simples apontar de um dedo [...]. Ontologias múltiplas convivem e podem ser incompatíveis entre si" (Almeida, 2013, p. 11-12).

De um lado, os índios do rio Negro estão instrumentalizados e são bastante habilidosos nas traduções. De outro, as incapacidades do Estado têm sido potencialmente devastadoras. Nessa espécie de encruzilhada de conhecimentos que se constitui na relação entre índios e Estado, há acúmulo e transformação em ambos os lados, por exemplo, no sentido apontado pelo seguinte pesquisador indígena: 
O levantamento trouxe novidades como comunidades e sítios anteriormente desconhecidos, famílias com diferentes trajetórias e uma complexa dinâmica de migração na própria Terra Indígena. (Pascoal Gonçalves, pesquisador indígena do PGTA da região do alto rio Negro e rio Xié)

Relacionando os dois termos trabalhados neste artigo - demarcação e gestão territorial -, é preciso dizer que o movimento de re-conhecimento e de re-territorializaçao é incessante e múltiplo. Minha hipótese é a de que, assim como as terras vividas pelos índios não cabem nos limites de uma concepção de demarcação, as mesmas também não caberão (sem dissonâncias) numa concepção estatal de gestão, pois, como é sabido, o Estado unifica e oblitera multiplicidades, onde os índios multiplicam e transcendem sentidos únicos. Diferentemente do território que o Estado esquadrinha, as territorialidades indígenas não são metrificáveis (e isso fica demonstrado em todos os projetos de cartografia e mapeamento realizados no rio Negro) e os recursos nelas distribuídos nem sempre são quantificáveis, por isso a importância do protagonismo indígena na gestão de suas terras.

As advertências que eles, os índios, nos fazem quanto a isso, são inúmeras e vêm de todos os lados. É o que se ouve dos Munduruku, quando estes falam que "sabem como funciona a lei da natureza através dos ensinamentos dos anciãos", "que os animais contribuem porque eles ensinam as coisas que não sabemos" e que "todos os animais têm quem cuide deles, eles têm mães, sejam peixes, sejam animais, aves, plantas, fogo, terra, vento, águas, até seres espirituais, todos têm vida". É também o que se ouve dos Kisêdjê que relatam que "os brancos estão provocando os espíritos da natureza, estão destruindo todas as florestas e que os espíritos não estão gostando disso e já começaram a se vingar" (Laboratório de Antropologias da T/terra, 2017). Mas é também o que dizem os rios que secam, os peixes que desaparecem, o sol que fica mais quente, as terras que não mais fertilizam... e essa linguagem é muito bem traduzida pelos índios (mas também por ambientalistas, permacultores, ecólogos, ribeirinhos, etc.). Por isso, os territórios são muitos e as gestões também. E essas concepções não deixam de ser constantemente decompostas, traduzidas, desconstruídas, 
traídas (assim como a guerra da epígrafe deste artigo). Ademais, não se pode ignorar que essas ações fazem parte do modo local de se fazer política - tanto interna, interétnica e indígena, quanto externa, com o Estado. As dissonâncias nas traduções realizadas pelos indígenas e pelo Estado podem ser lidas sob a lógica da guerra. Como lembra Latour (2002, p. 30):

[...] não há dúvidas de que a guerra dos mundos está acontecendo [...]. Ninguém pode constituir a unidade do mundo para outrem [...], oferecendo generosamente deixar os outros entrarem sob a condição de que abandonem à porte tudo o que lhes é caro: seus deuses, suas almas, seus objetos, seus tempos e seus espaços, em suma, a sua ontologia.

Assim, retomando nossa epígrafe: "pensar a guerra, em suma, é pensar como ela é levada a trair seu conceito", é pensar como índios e Estado são "levados" a improvisar no campo de batalhas que se desenha diariamente nas lutas conceituais e jurídicas, reais e virtuais em torno de terras, territórios e territorialidades.

A história do Brasil, da colonização, da ocupação territorial, de espoliação das terras e direitos indígenas, mostra como (pelo menos) dois conceitos de "guerra" podem coexistir em relações - pensando aqui nas relações entre índios e Estado nesses 517 anos de convivência. A "guerra" do Estado contra os índios continua, mais forte do que nunca, nas inúmeras investidas e tentativas de lhes usurpar direitos já conquistados (mas nunca efetivamente e seguramente garantidos), dentre os quais figura o direito à terra. Por outro lado, a "guerra" dos índios com o Estado também não cessa, tem, inclusive, se renovado. Os meios dessa guerra têm sido reinventados - mídias, discursos e vocabulários novos ou renovados - que passam a integrar o mundo indígena.

\section{Notas}

1 O Alto Rio Negro é um sistema complexo multiétnico e multilinguístico no qual cerca de 20 etnias, de quatro famílias linguísticas, operam trocas econômicas, rituais e matrimoniais. As quatro famílias linguísticas (e suas respectivas etnias) são: Arawak (etnias: Baniwa, Coripaco, Warekena, Tariano [atualmente adotou 
o tukano como língua] e Baré [que há muito fala nheengatu]; Tukano Oriental (Arapaso, Bará, Barasana, Desana, Karapanã, Kubeo, Makuna, Miriti-Tapuya, Piratapuia, Siriano, Tukano, Tuyuka, Kotiria/Wanano); Maku (Hup/Hupdah, Yuhup, Döw, Nadöb); Yanomami (que se situam de maneira transversa ao sistema, e por isso sua articulação deve ser tomada com cautela).

2 Agradeço imensamente a leitura dedicada e as contribuições feitas pelas organizadoras deste dossiê - Andressa Lewandowski e Julia Otero -, bem como pela/o parecerista anônima/o que fez sugestões valiosas, as quais, se não foram incorporadas nesta versão, serão desenvolvidas posteriormente. Este artigo é um dos resultados de pesquisa desenvolvida em um pós-doc financiado pela FAPESP (Processo $n^{\circ}$ 2016/03589-3), a quem agradeço. Também devo agradecimentos aos diversos comentários e sugestões feitas em diferentes oportunidades de diálogo nos últimos dois anos nas situações em que pude expor resultados parciais da pesquisa em andamentos na Universidade Estadual de Campinas, na Universidade Federal de São Carlos e no Laboratório de Antropologia da T/terra, da Universidade Nacional de Brasília.

3 A Foirn foi fundada em 1987. Conta com cerca de 80 associações filiadas, que contabilizam cerca de 40 mil pessoas, distribuídas em cerca de 700 comunidades em 30 milhões de hectares de floresta, dentre os quais, 11 milhões de hectares são de Terras Indígenas demarcadas.

4 O Alto Rio Negro tem alta concentração de territórios e povos indígenas. Lá estão localizadas sete Terras Indígenas (TIs), que, juntas, têm população total de 32.266 pessoas. As TIs da região são: Alto Rio Negro, Médio Rio Negro l, Médio Rio Negro 2, Balaio, Cué-Cué/Marabitanas, Rio Apapóris e Rio Tea. A extensão de todas as TIs do Rio Negro somadas é de mais de 11,5 milhões de hectares. Destes territórios, só um ainda não foi homologado pelo governo federal, a TI Cué-Cué/Marabitanas, que foi apenas declarada até o momento. As TIs homologadas do Alto Rio Negro se estendem por parte dos municípios de São Gabriel da Cachoeira, Santa Isabel do Rio Negro, Barcelos e Japurá, no norte do Amazonas. A maior parte destas TIs foi decretada no fim dos anos 1990, com exceção da Balaio. As histórias das reivindicações territoriais no Alto Rio Negro datam, pelo menos, desde a década de 1970. Para se ter uma noção, a primeira proposta oficial de demarcação foi feita pelo antropólogo da Fundação Nacional do Índio (FUNAI) Peter Silverwood-Cope, em 1975 e era referente à criação de um Território Federal Indígena do Alto Rio Negro. Quando tal proposta foi negada, em 1979, a FUNAI declarou a “ocupação indígena" de três áreas contíguas: Pari-Cachoeira, Iauaretê e Içana-Aiari. Essa declaração de "ocupação", no entanto, não significa "demarcação" e as reivindicações continuaram, sobretudo com o aumento da presença militar na região durante os anos 1980. Superadas diversas propostas (Colônias Indígenas e Florestas Nacionais, por exemplo), permeadas por desacordos os mais diversos - entre índios e agências estatais; entre líderes indígenas -, a declaração de cinco terras indígenas contíguas na região do alto e médio rio Negro (Médio Rio Negro I, Médio Rio Negro II, Rio Téa, Rio Apapóris e Alto Rio Negro) foi feita em dezembro de 1995. A homologação das mesmas se deu em 14 de abril de 1998, em uma cerimônia realizada na maloca da Federação das Organizações Indígenas do Rio Negro (FOIRN). Para saber mais sobre estes e outros processos referentes ao território no rio Negro, ver Ricardo \& Cabalzar (2006) e Buchillet (1991).

5 Produto final de uma pesquisa realizada durante o doutorado, minha tese refletiu sobre as políticas feitas pelos índios em diferentes instâncias, mas, principalmente, 
no movimento indígena e na prefeitura de São Gabriel da Cachoeira, ver Iubel (2015).

6 Para mais informações e uma análise detalhada sobre política e movimento indígena no alto rio Negro, ver também Andrello (2009; 2012).

7 "Nomos: regra, lei, norma. O primeiro sentido desta palavra é aquilo que se possui por partilha, aquilo que se usa porque atribuído por uma partilha; por extensão: uso, costume, conforme ao uso ou costume. Esta conformidade ao costume passa a significar a norma ou a regra costumeira de um comportamento de um grupo, as convenções sociais que o grupo estabelece para seus membros. Mais adiante: opinião geral, máxima geral, regra de conduta. Por extensão da regra e da máxima geral: uso ou costume com força de lei; ainda: o direito, o que se faz segundo o direito ou conforme ao direito. Nómos se opõe a phýsis: o nómos é o que é por convenção, por acordo e por decisão dos humanos, enquanto phýsis é o que é por natureza, por si mesmo independentemente da decisão ou vontade dos homens". (Chauí, 2002, p. 506)

8 O PCN era uma concentração de esforços de diferentes órgãos governamentais com o objetivo de desenvolver uma política de ocupação de 14 \% do território nacional situado ao norte das calhas dos rios Amazonas e Solimões. De início, a zona prioritária foi a faixa de fronteira, aonde se previa a instalação de várias unidades do Exército. Algumas das consequências diretas para os povos indígenas habitantes destas regiões foram a militarização, investimentos privados do setor mineral e a redução das terras a serem demarcadas (Andrello, 2009).

9 Vide a fala de Osmar Serraglio, Ministro da Justiça ligado aos interesses ruralistas, em entrevista ao Jornal Folha de São Paulo, em março de 2017: “O que acho é que vamos lá ver onde estão os indígenas, vamos dar boas condições de vida para eles, vamos parar com essa discussão sobre terras. Terra enche a barriga de alguém?". Essa entrevista foi concedida na mesma semana em que o ministro devolveu à Funai seis processos em fase de identificação (etapa anterior à homologação).

${ }^{10}$ Além dos membros do grupo formalmente constituído, o trabalho contou com a participação de outros atores da sociedade civil e de organizações internacionais, como o Instituto Internacional de Educação do Brasil - IEB, a TNC, e agências de cooperação internacional, como a Gesellschaft für Internationale Zusammenarbeit GIZ, a Cooperação Alemã para o Desenvolvimento - GmbH, o Programa das Nações Unidas para o Desenvolvimento - PNUD e o GEF (Comandulli, 2016, p. 47).

11 Sabe-se que "governança" é um termo com muitos predicados e múltiplos sentidos. É palavra de ordem tanto na pauta do chamado "desenvolvimento sustentável", no mercado das ONGs e tem sido bastante elaborado por "economistas verdes", como Elinor Ostrom, e alguns antropólogos, como Emílio Moram. Agradeço a/ao parecerista anônima/o deste artigo pela observação a respeito dessa multiplicidade de sentidos e de origens possíveis do termo "governança" e pretendo desenvolver um debate mais aprofundado sobre os usos que o termo vem recebendo no alto rio Negro a partir das ações e reflexões promovidas pela PNGATI em outro momento.

12 Além disso, a título de hipótese, que poderia ser confirmada caso se procedesse a uma espécie de exercício arqueológico a respeito do termo governança dentro do próprio Estado, penso que, do perspectiva deste, a proposta (ou imposição) do termo "governança" (e suas implicações) aos povos indígenas poderia conduzir a uma reflexão sobre o "governar junto". Entretanto, creio que aqui novamente encontraríamos um terreno em que índios e Estado não necessariamente pensam 
a mesma coisa a respeito de ideias como "governo" e "trabalho" (coletivo ou individual), por exemplo, para nos atermos a apenas duas.

13 Como já apontado, o alto rio Negro é complexo multilíngue (Sorensen, 1967; Jackson, 1983; Stenzel, 2005) onde pratica-se, com algumas poucas exceções, o casamento com exogamia linguística (Sorensen, 1967; C. Hugh-Jones, 1979). Um casal é geralmente composto por cônjuges de povos diferentes, às vezes falantes de línguas diferentes, o que faz com que os filhos desse casal aprendam pelo menos duas línguas - a da mãe e a do pai -, além do português que é aprendido nas escolas desde a instalação das missões salesianas na região, e não raramente também do espanhol, falado por quase todos seus parentes.

${ }^{14}$ Uma importante consideração a respeito da ideia de tradução - na antropologia e no mundo indígena - que não pode ser ignorada aqui é aquela aventada por Bruce Albert e Davi Kopenawa (2015), da tradução como "ação política". É este, certamente, o tipo de tradução empreendida por André Baniwa a que estou fazendo referência no presente artigo.

15 Missões salesianas começaram a ser implantadas por todo o Alto Rio Negro a partir de 1914. As atividades missionárias consistiam, dentre outras coisas, na educação escolar das crianças, que era realizado em regime de internato. O principal objetivo das missões era, evidentemente, a conversão dos índios ao catolicismo e, para isso, pensava-se na educação como meio mais eficaz. Com a implantação de grandes colégios internos em alguns distritos de São Gabriel da Cachoeira, bem como na própria sede do município, boa parte das crianças da geração que hoje tem entre 40 e 60 anos foi afastada do convívio com as gerações mais velhas, o que implicou no enfraquecimento de algumas "tradições" e de algumas línguas indígenas (mas não no desaparecimento das mesmas). Os internatos começaram a ser fechados na década de 1970, com o aumento também da presença militar e estatal na região. Vários dos antigos colégios religiosos são atualmente mantidos pelos governos estaduais e municipais, embora os religiosos ainda tenham bastante ingerência sobre os mesmos. Além disso, tem crescido o número de escolas indígenas na região.

\section{Referências}

ALBERT, Bruce; KOPENAWA, Davi. A queda do céu. São Paulo: Companhia das Letras, 2015.

ALMEIDA, Mauro Barbosa. Caipora e outros conflitos ontológicos. R@U - Revista de Antropologia da UFSCar, São Carlos, v. 5, n. 1, p. 7-28, 2013.

ANDRELLO, Geraldo. Cidade do índio: transformações e cotidiano em Iauaretê. São Paulo: Editora UNESP: ISA; Rio de Janeiro: NUTI, 2006.

ANDRELLO, Geraldo. Política Indígena no rio Uaupés: hierarquia e alianças. Teoria \& Pesquisa, [S.l.], v. XVII, p. 81-96, 2009.

ANDRELLO, Geraldo. Histórias tariano e tukano. Política e ritual no rio Uaupés. Revista de Antropologia USP, São Paulo, v. 55, p. 291-330, 2012. 
BOLETIM GOVERNANÇA E BEM VIVER INDÍGENA: Planos de Gestão Territorial e Ambiental das Terras Indígenas do Alto e Médio Rio Negro, n. 2. Foirn; Instituto Socioambiental; Funai, novembro de 2016.

BUCHILLET, Dominique. Pari Cachoeira: o laboratório Tukano do projeto Calha Norte. Povos Indígenas no Brasil 1987/88/89/90. Centro Ecumênico de Documentação e Informação (CEDI), 1991.

CABAlZAR, A.; RICARDO, B. (org.). Povos indígenas do Rio Negro: uma introdução à diversidade socioambiental do noroeste da Amazônia brasileira. São Paulo: Instituto Socioambiental; São Gabriel da Cachoeira, AM: FOIRN - Federação das Organizações Indígenas do Rio Negro, 2006.

CARNEIRO DA CUNHA, Manuela. Índios no Brasil: História, direitos e cidadania. São Paulo: Claroenigma, 2012.

CHAUÍ, Marilena. Introdução à história da filosofia: dos pré-socráticos a Aristóteles. São Paulo: Companhia das Letras, 2002.

FOLHA DE SÃO PAULO. Ministro da Justiça critica índios e diz que "terra não enche barriga". 10 de março de 2017.

GOVERNANÇA E BEM VIVER INDÍGENA. Foirn, Funai e ISA, julho de 2016.

GOVERNANÇA E BEM VIVER INDÍGENA. Foirn, Funai e ISA, novembro de 2016.

HUGH-JONES, Christine. From the Milk River: Spatial and Temporal Processes in North-west Amazonia. Cambridge: Cambridge University Press, 1979.

IUBEL, Aline Fonseca. Transformações políticas e indígenas: Movimento e Prefeitura no Alto Rio Negro. 2015. Tese (Doutorado) Programa de Pós-Graduação em Antropologia Social da UFSCar, São Carlos, 2015.

JACKSON, Jean. The Fish People: Linguistic Exogamy and Tukanoan Identity in Northwest Amazonia. Cambridge: Cambridge University Press, [1972] 1983.

JULLIEN, François. Tratado de Eficácia. São Paulo: Ed. 34, 1998.

LABORATÓRIO DE ANTROPOLOGIAS DA T/TERRA. EntreTerras, Brasília, v. 1, n. l, junho 2017.

LATOUR, Bruno. The Pasteurization of France. Harvard, 1993.

LATOUR, Bruno. War of the Worlds. Chicago: Prickly Paradigm Press, 2002. 
LEACH, J. Modes of creativity. In: HIRSCH, E.; STRATHERN, M. (org.). Transactions and Creations: Property Debates and the Stimulus of Melanesia. New York: Berghan Books, 2004.

LÉVI-STRAUSS, Claude. O Cru e o Cozido: Mitológicas 1. São Paulo: Cosac e Naify, 2004.

MATOS, Marcos de Almeida. Cosmopolemos: notícias de uma guerra de mundos. In: COLÓQUIO INTERNACIONAL MIL NOMES DE GAIA: DO ANTROPOCENO À IDADE DA TERRA, realizado entre os dias 15 e 19 de setembro de 2014 na Fundação Casa de Rui Barbosa. Anais [...] Rio de Janeiro, 2014.

MIRAS, Júlia Trujillo. Demarcação e Equivocação: uma reflexão a partir do caso da Terra Indígena Krĩkati. R@U - Revista de Antropologia da UFSCar, São Carlos, v. 9, n. 1, 2017.

PERRONE-MOISÉS, Beatriz. Festa e Guerra. Tese apresentada ao Concurso de títulos e provas visando à obtenção do Título de LivreDocente. USP. São Paulo, 2015.

RICARDO, C. A. Jogo duro na Cabeça do Cachorro. Aconteceu Especial 18 (Povos Indígenas no Brasil 1987/88/89/90). São Paulo: CEDI, 1991. p. 101-106.

SILVERWOOD-COPE, P. Projeto de Emergência para as Comunidades do Alto Rio Negro. Brasília: Funai, 1976.

SORENSEN, A. Multilingualism in the Northwest Amazon. American Anthropologist, [S.l.], v. 69, 1967.

STENZEL, K. Multilingualism in the Northwest Amazon, revisited. In: CONGRESO DE IDIOMAS INDÍGENAS DE LATINOAMÉRICA-II, p. 2729 de octubre de 2005, University of Texas at Austin. Anais [...], Texas, Austin, 2005.

WEBER, Max. História Agrária Romana. São Paulo: Martins Fontes, 1994.

Recebido em 03/11/2017

Aceito em 12/03/2018

\section{Aline Fonseca Iubel}

Doutora em Antropologia Social

Pós-doutorando em Antropologia Social, Universidade Estadual de Campinas,

Campinas, Brasil

E-mail: alineiubel@gmail.com 